\title{
Systolic and Diastolic Properties of Univentricular Hearts in Children: Insights from Physiologic Indices That Reflect Calcium Cycling
}

\author{
FRANCINE G. ERENBERG AND ANIRBAN BANERJEE \\ Division of Pediatric Cardiology [F.G.E., A.B.], Children's Hospital Medical Center, Cincinnati, Ohio, \\ U.S.A.; and Division of Pediatric Cardiology [A.B.], Tufts-New England Medical Center, Boston, \\ Massachusetts 02111, U.S.A.
}

\begin{tabular}{|c|c|}
\hline \multicolumn{2}{|c|}{ ABSTRACT } \\
\hline 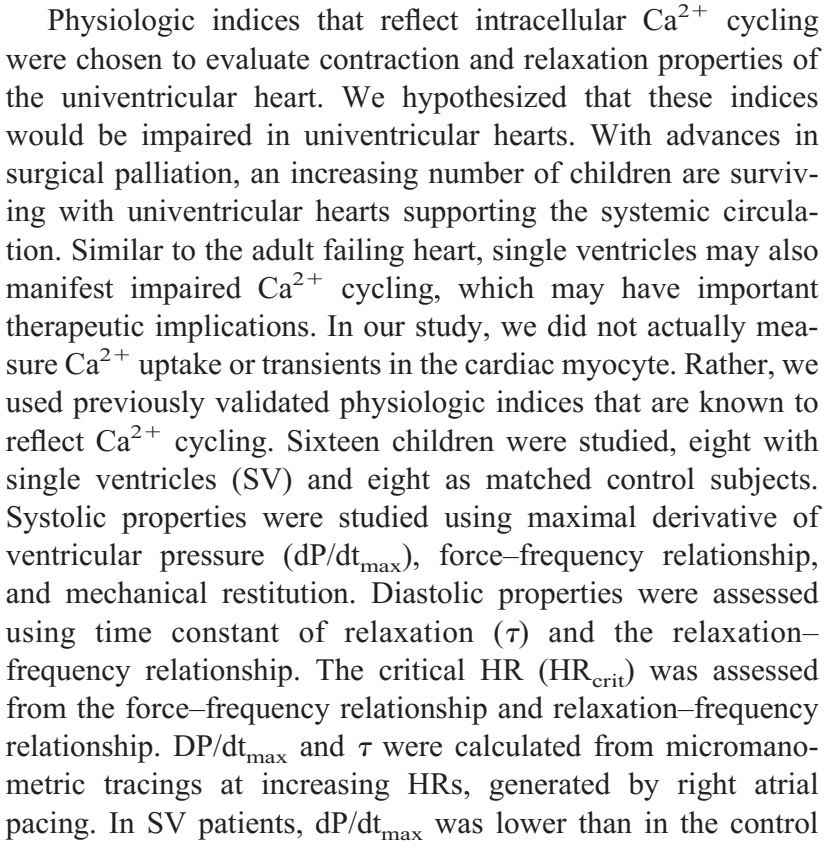 & 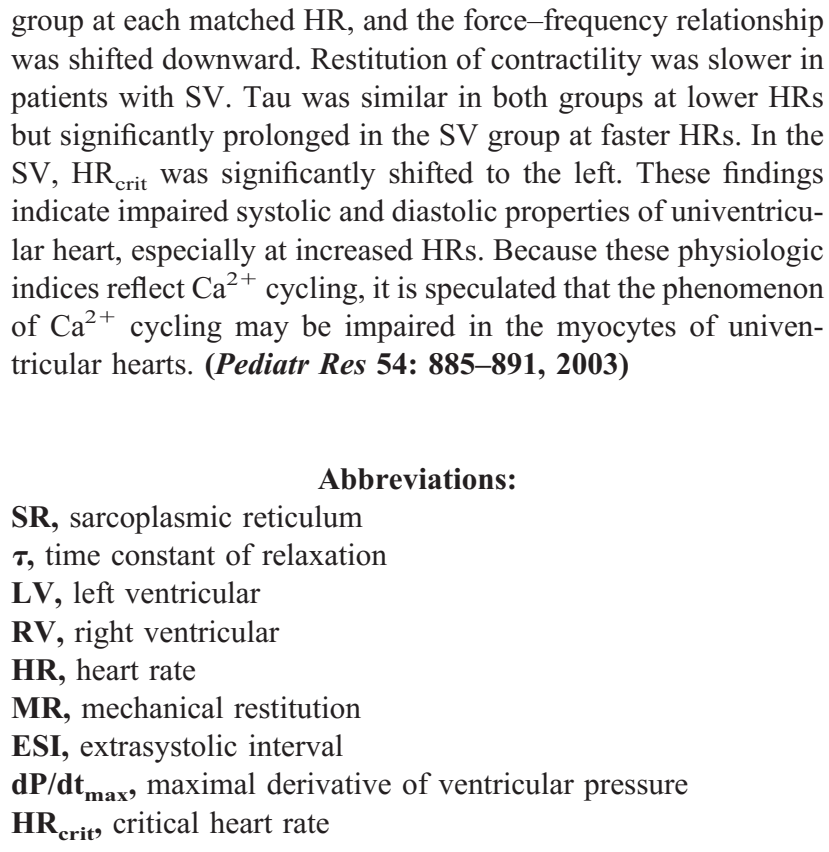 \\
\hline
\end{tabular}

Recent advances in the surgical management of congenital heart disease have resulted in many children that have surgical palliations consisting of univentricular hearts that must support the systemic circulation. It has been both theorized and observed in clinical practice that these hearts with single ventricles may be predisposed to dysfunction or failure (1). Several previous assessments have measured systolic function in univentricular hearts using noninvasive techniques, such as echo-

Received March 13, 2002; accepted June 2, 2003.

Correspondence: Anirban Banerjee, MD, Division of Pediatric Cardiology, Floating Hospital for Children, Tufts-New England Medical Center, 750 Washington Street, \#313, Boston, MA 02111; email: abanerjee@tufts-nemc.org

Supported by postdoctoral fellowship grant from the American Heart Association, Ohio-West Virginia Affiliate.

DOI: 10.1203/01.PDR.0000090930.17613.D8 cardiography $(2,3)$, magnetic resonance imaging (4), and radionuclide angiography (5), and often found it to be decreased compared with controls. Diastolic function of the univentricular heart has been investigated by echocardiography and radionuclide angiography $(6,7)$. Despite these noninvasive investigations, the true physiologic assessment of systolic and diastolic properties using invasive indices is infrequent in children (8) and has never been performed in univentricular hearts.

The calcium ion $\left(\mathrm{Ca}^{2+}\right)$ plays a crucial role in the excitationcontraction coupling in the cardiac myocyte. The coupling leads to intracellular $\mathrm{Ca}^{2+}$ release and reuptake by the sarcoplasmic reticulum (SR), two events that are essential for myocyte contraction and relaxation, respectively. Both in animals and in humans with heart failure, it has been shown conclu- 
sively that intracellular $\mathrm{Ca}^{2+}$ cycling is impaired, which in turn results in systolic and diastolic dysfunction $(9,10)$. We propose that similar to the adult failing heart, single ventricles may also manifest impaired $\mathrm{Ca}^{2+}$ cycling. If we can prove that $\mathrm{Ca}^{2+}$ cycling is indeed impaired, then it may provide a future incentive for pharmacologic therapy or genetic therapy, aimed specifically at improving $\mathrm{Ca}^{2+}$ cycling. For example, inhibition of phospholamban or stimulation of $\mathrm{Ca}^{2+}$ uptake and release by SR by pharmacologic means may help in improving diastolic and systolic function in this group of patients. In the future, patients with single ventricles will form a sizable number of patients with congenital heart disease who will be followed by pediatric and adult cardiologists. Therefore, it is very important to take the first step to determine whether $\mathrm{Ca}^{2+}$ cycling is truly impaired in this group of patients.

In our study, we did not actually measure $\mathrm{Ca}^{2+}$ uptake and $\mathrm{Ca}^{2+}$ transients in the cardiac myocyte. Rather, we used physiologic indices that are known to reflect $\mathrm{Ca}^{2+}$ cycling. The phenomenon of $\mathrm{Ca}^{2+}$ release by the SR was studied by the force-frequency relationship (11) and by mechanical restitution of contractility (12). $\mathrm{Ca}^{2+}$ uptake by the SR was studied by evaluating time constant of relaxation $(\tau)(13)$ and the relaxation-frequency relationship (14). Therefore, this investigation had two aims: 1) to assess systolic and diastolic properties of the univentricular heart in young children, using invasive techniques, and 2) to evaluate the physiologic aspect of $\mathrm{Ca}^{2+}$ cycling in single ventricles. We hypothesized that systolic and diastolic properties would be impaired in univentricular hearts of children.

\section{METHODS}

\section{Patient Population}

Patients with functional single ventricles of either left (LV) or right ventricular (RV) morphology composed the experimental group, and those with two normal ventricles constituted the control group. Written informed consent was obtained from the parents of all patients, and the experimental protocol was approved by the Institutional Review Board. We studied a total of 16 children. The experimental group consisted of eight children, five of whom had single LV (tricuspid atresia $=3$, double inlet left ventricle with L-transposition of great arteries and aortic hypoplasia $=2$ ), and three of whom had single, systemic RV (hypoplastic left heart syndrome $=2$, severely unbalanced atrioventricular septal defect with dominant right ventricle $=1$ ). The control group consisted of eight agematched control subjects with normal, nonhypertrophied left ventricles based on echocardiograms (mild pulmonic stenosis $=3$; mild coarctation of the aorta $=1$; small patent ductus arteriosus $=3$; and small bronchial collateral, otherwise normal heart $=1$ ). In the patients with pulmonic stenosis, there was no evidence of flattening or compression of the interventricular septum toward the left ventricle. In the patients with coarctation of aorta, the gradient was mild $(<15 \mathrm{~mm} \mathrm{Hg})$ and there was no evidence of left ventricular hypertrophy by echocardiography. Single-ventricle patients with more than mild regurgitation of systemic atrioventricular valve or with outlet obstruction noted by echocardiography were excluded from this study. Some control patients underwent cardiac catheterizations as a result of discrepant noninvasive findings.

\section{Techniques}

All studies were performed in the cardiac catheterization laboratory under sedation with oral chloral hydrate $(75 \mathrm{mg} / \mathrm{kg})$ followed by parenteral ketamine $(1 \mathrm{mg} / \mathrm{kg})$ and/or midazolam $(0.05 \mathrm{mg} / \mathrm{kg}$ i.v.). For reducing the effects of endogenous catecholamine during arousal, sedation was maintained at a steady state by monitoring state of arousal, heart rate (HR), and blood pressure just before the experimental protocol. When needed, small boluses of midazolam were given i.v., and no ketamine was used before the experimental protocol. Highfidelity ventricular pressure measurements were performed at end-expiration by a 2 French Millar micromanometric catheter (Millar Instruments, Houston, TX, U.S.A.) introduced through the lumen of a pigtail catheter positioned in the ventricle. A bipolar pacing catheter was placed in the high right atrium, and ventricular pressure tracings were recorded during high atrial pacing at HRs of $110,120,130,140,150,160,170$, and 180 $\mathrm{bpm}$. Two-dimensional echocardiography was performed to obtain end-diastolic and end-systolic ventricular volumes at a HR of $130 \mathrm{bpm}$, using the Simpson's biplane technique. Proper catheter placement was assessed by fluoroscopy, before the initiation of pacing.

\section{Measurements and Calculations}

Systolic properties. For determination of systolic function, values of the maximal derivative of pressure $\left(\mathrm{dP} / \mathrm{dt}_{\max }\right)$ from four ventricular pressure tracings at end-expiration were averaged to obtain the value of $\mathrm{dP} / \mathrm{dt}_{\max }$ at each of the abovementioned HRs. At an $\mathrm{HR}$ of $130 \mathrm{bpm}, \mathrm{dP} / \mathrm{dt}_{\max }$ was corrected for preload by dividing it with the end-diastolic volume. Thereafter, the response of isovolumic contraction to incremental atrial pacing was examined by plotting $\mathrm{dP} / \mathrm{dt}_{\max }$ against $\mathrm{HR}$. This generated the force-frequency relationship. Within the control group, the change in $\mathrm{dp} / \mathrm{dt}_{\max }$ was compared between the baseline state $(\mathrm{HR}=110 \mathrm{bpm})$ and an HR of $150 \mathrm{bpm}$ and thereafter between an HR of 150 and $180 \mathrm{bpm}$. In the experimental group, the $\mathrm{dp} / \mathrm{dt}_{\max }$ was compared between the baseline state and the critical HR and between the critical HR and an HR of $180 \mathrm{bpm}$.

Mechanical restitution (MR) is the phenomenon of restoration of contractility in premature beats, introduced at progressively longer extrasystolic intervals (ESIs) (see Fig. 1). During atrial pacing at a constant cycle length of $450 \mathrm{~ms}$, premature beats were generated at increasing ESIs. Ventricular $\mathrm{dP} / \mathrm{dt}_{\max }$ of the premature beat was measured and normalized by the $\mathrm{dP} / \mathrm{dt}_{\max }$ of the preceding, steady-state beat and expressed as a percentage. This normalized $\mathrm{dP} / \mathrm{dt}_{\max }$ of the gradually introduced premature beats was plotted against the gradually prolonging ESI to generate MR curves. Previous studies in isolated and intact heart preparations have clearly shown the relative load independence of MR $(15,16)$. For generating MR curves in our study, steady-state pacing was instituted at a cycle length of $450 \mathrm{~ms}$ (HR of $133 \mathrm{bpm}$ ) and maintained for 1 min. A premature (extrasystolic) beat was then introduced at an 


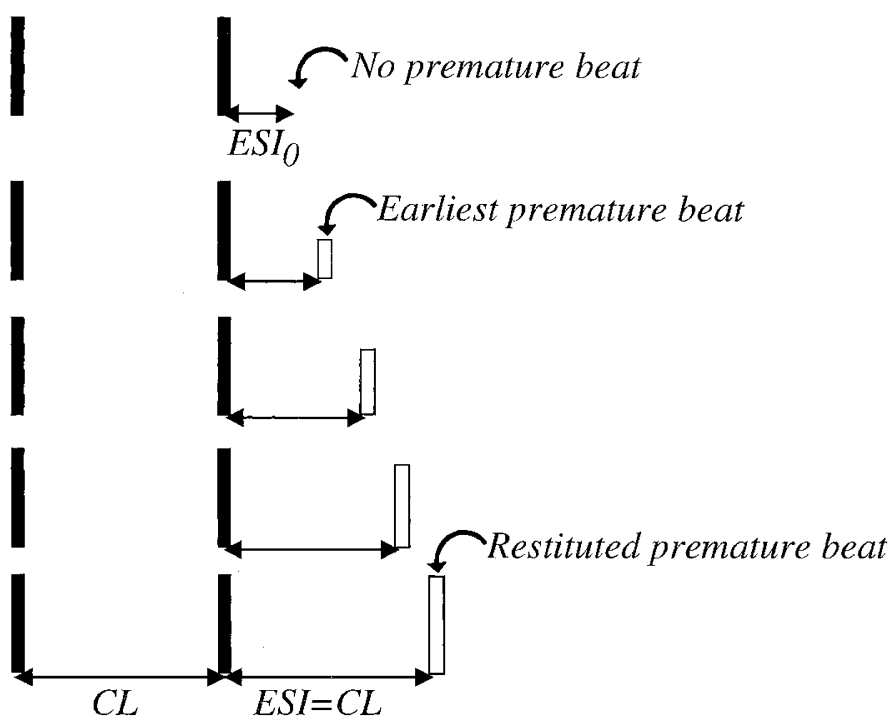

Figure 1. Schematic diagram that exlains the phenomenon of MR. Two normal-paced beats (black bars) at constant cycle length (CL) are followed by a premature beat (white bar). The height of the each bar arbitrarily represents the strength of contraction of that beat. The coupling interval between the last paced beat and the premature beat is the ESI. $\mathrm{ESI}_{0}$ is the longest ESI at which no mechanical contraction develops. As the ESI is increased, the strength of contraction of the premature beat increases. When the ESI equals the pacing cycle length, the premature beat regains its full strength of contraction; this phenomenon is known as MR.

ESI of $200 \mathrm{~ms}$ when no force of contraction was noted. Thereafter, further premature beats were introduced as the ESI was increased at increments of $20 \mathrm{~ms}$ up to an ESI of $450 \mathrm{~ms}$. MR curves were obtained from a monoexponential function (17):

$$
\mathrm{dP} / \mathrm{dt}_{\max }(\mathrm{ES}) / \mathrm{dP} / \mathrm{dt}_{\max }(\mathrm{SS})=\mathrm{CR}_{\max }\left[1-\exp \left(-\mathrm{ESI}_{-} \mathrm{ESI}_{0}\right) / \mathrm{T}_{\mathrm{c}}\right]
$$

where $\mathrm{dP} / \mathrm{dt}_{\max }(\mathrm{ES})$ is the maximum $\mathrm{dp} / \mathrm{dt}$ of the extra systolic beat, $\mathrm{dP} / \mathrm{dt}_{\max }(\mathrm{SS})$ is the maximum $\mathrm{dp} / \mathrm{dt}$ of the preceding steady-state beat, $\mathrm{ESI}_{0}$ is the longest ESI at which no mechanical contraction develops, ESI is the coupling interval between the last steady-state contraction and the premature contraction, $\mathrm{CR}_{\max }$ is the normalized plateau value of the MR curve, and $\mathrm{T}_{\mathrm{c}}$ is the time constant of MR and an indicator of rapidity of MR.

Diastolic properties. Time constant of relaxation. The active relaxation phase of diastolic function was assessed by the time constant of isovolumic relaxation. Isovolumic relaxation period was defined as the period from the peak negative $\mathrm{dP} / \mathrm{dt}$ to $5 \mathrm{~mm} \mathrm{Hg}$ above the ventricular end-diastolic pressure of the following beat. Tau was derived from the micromanometric ventricular pressure tracings by the Weiss method, which assumes a monoexponential fall in pressure to a zero asymptote (18). An average value for $\tau$ was calculated at a high sampling rate of $3 \mathrm{~ms}$ from four beats at end-expiration. All comparisons between patients were performed at constant HR generated by atrial pacing. During incremental pacing, the relaxationfrequency relationship was derived by plotting $\tau$ versus HR. Comparisons within each group were performed in a manner identical to that used for the force-frequency relationship.

Critical HR. Critical HR ( $\left.\mathrm{HR}_{\text {crit }}\right)$ was defined as the HR at which the force-frequency and relaxation-frequency relation- ships reached their peak and nadir, respectively. The value of the HR beyond which $\mathrm{dP} / \mathrm{dt}_{\max }$ decreased and $\tau$ increased by $5 \%$, respectively, was the $\mathrm{HR}_{\text {crit }}$ for isovolumic contraction and relaxation, respectively (14).

\section{Statistics}

Data are expressed as mean $\pm \mathrm{SD}$, unless otherwise stated. Patients with single ventricles were compared with the control patients with normal left ventricles by the unpaired $t$ test. ANOVA with Bonferroni correction was used to test means during pacing at increasing HRs. A linear regression analysis was performed to calculate correlation coefficients. For multiple variables that may influence one another, a partial correlation matrix was created. $P<0.05$ was considered to be statistically significant.

\section{RESULTS}

\section{Clinical Data}

The clinical variables of the single-ventricle and control groups are shown in Table 1. An important characteristic was that the average ventricular volume of the univentricular heart was significantly higher than that of the control heart, at a matched HR $\left(97.8 \pm 29.6\right.$ versus $48.5 \pm 15.3 \mathrm{~mL} / \mathrm{m}^{2}, p<$ $0.05)$. The morphology of each univentricular heart and its surgical stage are outlined in Table 2. Two patients with single ventricles had trivial to mild regurgitation of the systemic atrioventricular valve. In both of these patients, the morphology of the single ventricle was of the RV type. None of the patients in the single-ventricle group had any evidence of outlet obstruction. The baseline ejection fraction showed no significant difference between the control and experimental groups (Table 1).

\section{Systolic Properties}

In the single-ventricle group, $\mathrm{dP} / \mathrm{dt}_{\max }$ was lower than that in the control group at a matched HR (Fig. 2). Even when

Table 1. Clinical variables

\begin{tabular}{lccc}
\hline \multicolumn{1}{c}{ Variables } & $\begin{array}{c}\text { Single-ventricle group } \\
(n=8)\end{array}$ & $\begin{array}{c}\text { Control group } \\
(n=8)\end{array}$ & $p$ value \\
\hline Age $(\mathrm{y})$ & $2.17 \pm 1.2$ & $3.19 \pm 1.5$ & $\mathrm{NS}$ \\
& $($ range: $0.37-3.5)$ & $($ range: $0.5-4.8)$ & \\
Male & 3 & 5 & \\
Female & 5 & 3 & \\
Weight $(\mathrm{kg})$ & $11.9 \pm 3.8$ & $13.5 \pm 7.0$ & $\mathrm{NS}$ \\
Height $(\mathrm{cm})$ & $80.2 \pm 14.5$ & $92.3 \pm 29.6$ & $\mathrm{NS}$ \\
BSA $\left(\mathrm{m}^{2}\right)$ & $0.6 \pm 0.1$ & $0.65 \pm 0.2$ & $\mathrm{NS}$ \\
$\mathrm{HR}(\mathrm{bpm})$ & $119 \pm 18.3$ & $109 \pm 12.4$ & $\mathrm{NS}$ \\
Systolic BP $(\mathrm{mm} \mathrm{Hg})$ & $98 \pm 14$ & $104 \pm 16$ & $\mathrm{NS}$ \\
Diastolic BP $(\mathrm{mm} \mathrm{Hg})$ & $52 \pm 8$ & $60 \pm 7$ & $\mathrm{NS}$ \\
$\mathrm{O}_{2}$ Saturation $(\%)$ & $84 \pm 5$ & $98 \pm 2$ & $<0.05$ \\
EDP $(\mathrm{mm} \mathrm{Hg})$ & $9 \pm 4$ & $8 \pm 3$ & $\mathrm{NS}$ \\
Ejection fraction $_{\text {EDV }}\left(\mathrm{ml} / \mathrm{m}^{2}\right)$ & $55 \pm 9$ & $61 \pm 8$ & $\mathrm{NS}$ \\
FD $_{130}$ & $97.8 \pm 29.6$ & $48.5 \pm 15.3$ & $<0.05$ \\
\hline
\end{tabular}

BSA, body surface area; BP, blood pressure; EDP, end-diastolic pressure of single ventricle/left ventricle; $\mathrm{EDV}_{130}$, end-diastolic volume of single ventricle/left ventricle normalized for BSA and measured at an HR of $130 \mathrm{bpm}$; NS, not significant. 
Table 2. Ventricular morphology and surgical stage in individual patients with univentricular hearts

\begin{tabular}{rccc}
\hline $\begin{array}{c}\text { Patient } \\
\text { no. }\end{array}$ & Age $(\mathrm{y})$ & $\begin{array}{c}\text { Ventricular } \\
\text { morphology }\end{array}$ & Surgical stage \\
\hline 1 & 3.1 & RV & Post-BDG, Pre-Fontan \\
10 & 3.2 & RV & Post-BDG, Pre-Fontan \\
15 & 2.4 & RV & Post-BDG, Pre-Fontan \\
4 & 2.0 & LV & Post-BDG, Pre-Fontan \\
12 & 1.9 & LV & Post-BDG, Pre-Fontan \\
14 & 2.7 & LV & Post-BDG, Pre-Fontan \\
16 & 2.4 & LV & Post-BDG, Pre-Fontan \\
17 & 3.5 & LV & Post-BDG, Pre-Fontan
\end{tabular}

BDG, bidirectional Glenn shunt; BTS, modified Blalock-Taussig shunt.

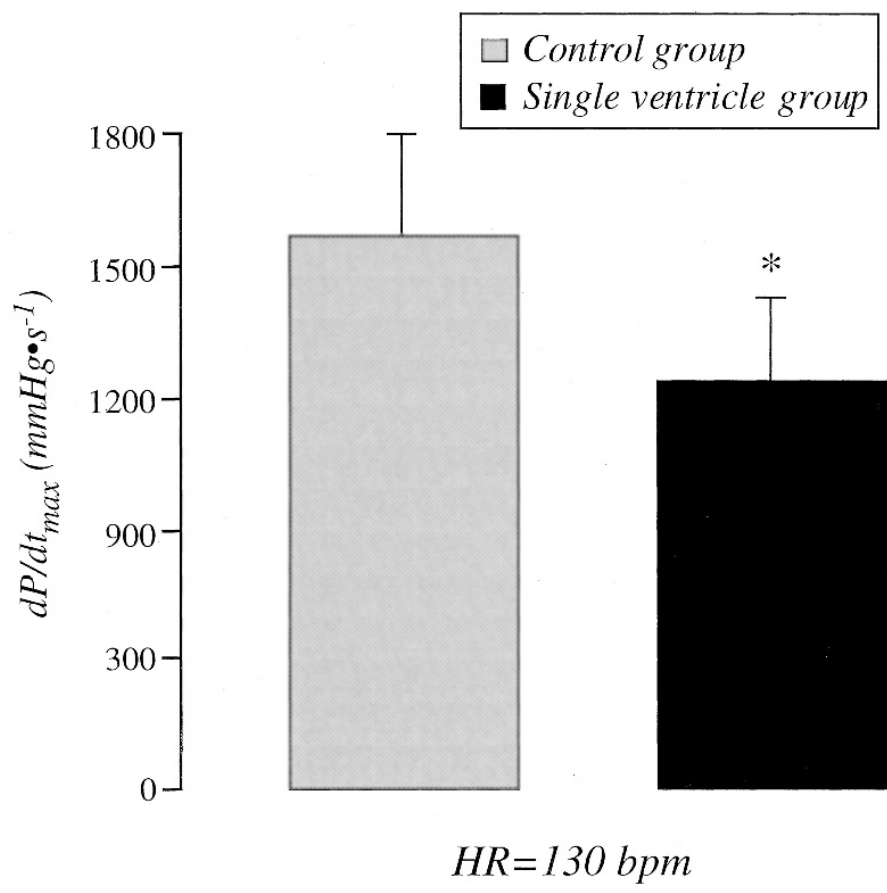

Figure 2. Contraction measured by $\mathrm{dP} / \mathrm{dt}_{\text {max }}$ at a constant $\mathrm{HR}$ of $130 \mathrm{bpm}$ was lower in the single-ventricle group than in the control group. Error bars represent $\mathrm{SD}(* p<0.01)$.

corrected for preload, $\mathrm{dP} / \mathrm{dt}_{\max }$ of the single-ventricle group was significantly lower $\left(20.6\right.$ versus $51.8 \mathrm{~mm} \mathrm{Hg} \cdot \mathrm{s}^{-1} \cdot \mathrm{ml}^{-1}$; $p<0.01)$. The force-frequency relationship $\left(\mathrm{dP} / \mathrm{dt}_{\max }\right.$ versus HR) in the control group was characterized by a gradual increase in $\mathrm{dP} / \mathrm{dt}_{\max }$ with each increment in HR (Fig. 3). Within the control group, there was a significant increase in $\mathrm{dP} / \mathrm{dt}_{\max }$ between the baseline state and HRs of 150 and 180 $\mathrm{bpm}$. In the single-ventricle group, the force-frequency relationship was also characterized initially by an increase in $\mathrm{dP} / \mathrm{dt}_{\max }$ with incremental increase in HR. However, there were two major differences (Fig. 3). First, the entire forcefrequency relationship was shifted downward as a result of a lower $\mathrm{dP} / \mathrm{dt}_{\max }$ at each matched HR $(p<0.01$ control versus experimental group). Second, when the pacing rate exceeded the $\mathrm{HR}_{\text {crit }}$, instead of increasing any further, $\mathrm{dP} / \mathrm{dt}_{\max }$ decreased.

$\boldsymbol{H R}_{\text {crir }}$ In all patients with univentricular hearts, $\mathrm{HR}_{\text {crit }}$ was reached between HRs of 140 and $160 \mathrm{bpm}($ mean $=146.5 \pm$ $11.8 \mathrm{bpm}$ ). In control hearts, the force-frequency relationship

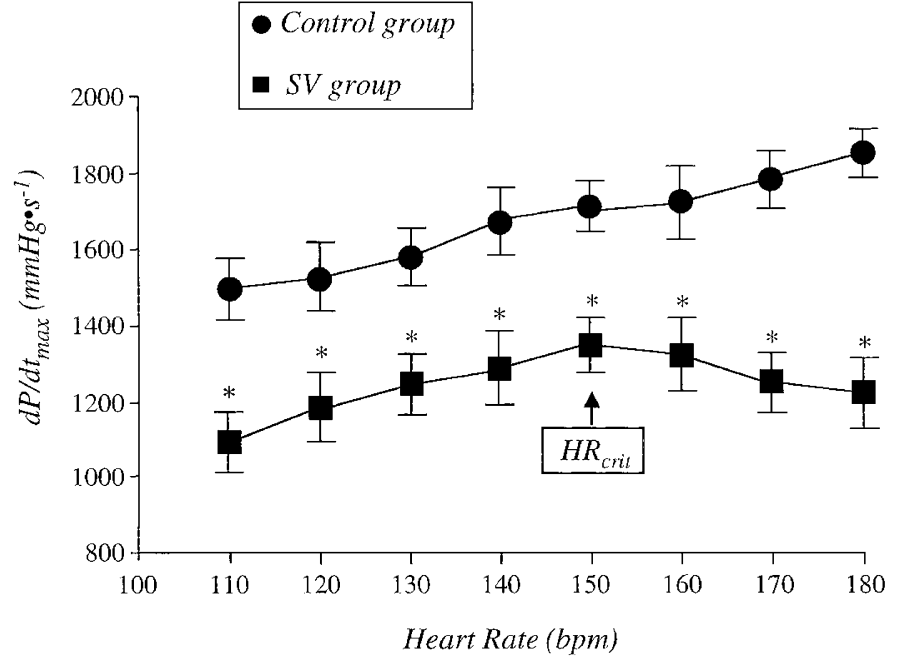

Figure 3. Force-frequency relationship ( $\left.\mathrm{dP} / \mathrm{dt}_{\max } v s \mathrm{HR}\right)$ is depicted in the single-ventricle $(\square)$ and control $(\bullet)$ groups. In the control group, $\mathrm{dP} / \mathrm{dt}_{\max }$ increased with increments in HR, producing a positive force-frequency relationship. In the single-ventricle group, $\mathrm{dP} / \mathrm{dt}_{\max }$ was lower at each $\mathrm{HR}$, and the entire force-frequency relationship was shifted downward. Moreover at HRs exceeding $150 \mathrm{bpm}\left(\mathrm{HR}_{\text {crit }}\right)$, the force-frequency relationship changed from positive to negative. Error bars represent SEM $\left({ }^{*} p<0.01\right.$ between experimental and control groups). SV, single-ventricle group.

often reached a plateau at $\mathrm{HRs}$ of 170 and $180 \mathrm{bpm}$, but $\mathrm{HR}_{\text {crit }}$ was not achieved in the range of HRs studied in this experiment. This suggests that the value of $\mathrm{HR}_{\text {crit }}$ in control patients either is equal to or exceeds $180 \mathrm{bpm}$. For statistical comparison, $\mathrm{HR}_{\text {crit }}$ value of $180 \mathrm{bpm}$ was used in the control group. This comparison showed that in univentricular hearts, the $\mathrm{HR}_{\text {crit }}$ was significantly shifted to the left $(p<0.001)$.

MR. MR was impaired in patients with single ventricles. This was evident by the slower ascending limb of the MR curve and the delayed achievement of peak response in patients with single ventricles (Fig. 4). The time constant of MR ( $\left.T_{c}\right)$, an indicator of the rapidity of MR, was significantly prolonged in patients with single ventricles $(56.7 \pm 8.7 \mathrm{~ms}$ versus $78.4 \pm$ $10.3 \mathrm{~ms} ; p<0.001)$.

\section{Diastolic Properties}

Relaxation. Isovolumic relaxation was similar in both groups at lower HRs but significantly prolonged in single ventricles at higher HRs (Fig. 5). The relaxation-frequency relationship ( $\tau$ versus HR) also showed a characteristic difference between the two groups (Fig. 6). At lower HRs, both groups showed a gradual decrease in $\tau$ with increasing HR, and no significant statistical divergence was noted between the two groups. In contrast, at higher HRs ( $\geq 140 \mathrm{bpm})$, a significant divergence was noted between the two groups. In the univentricular group, the curves diverged and assumed a biphasic relationship. This biphasic relationship was characterized by an initial negative limb, during which $\tau$ became shorter with every increment in HR. However, at the $\mathrm{HR}_{\text {crit, }}$, the relationship became abruptly positive, indicating impaired relaxation. The positive limb continued upward, produced by further prolongation of $\tau$ with further increments in HRs. 


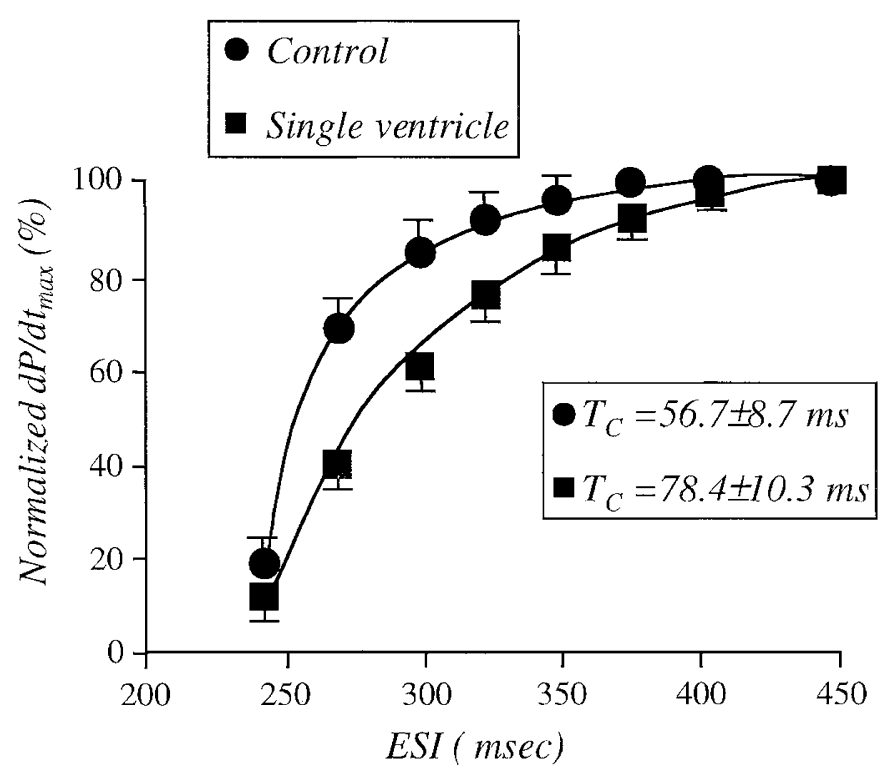

Figure 4. MR curve from patients with single ventricles $(\boldsymbol{\square})$ and control patients (-), generated by varying the ESI. The process of restitution of contractility was slower in the patient with single ventricle. This is reflected by a restitution curve that is less steep and has a longer time constant of restitution $\left(T_{c}\right)$. There was delayed achievement of peak response. Error bars represent SEM.

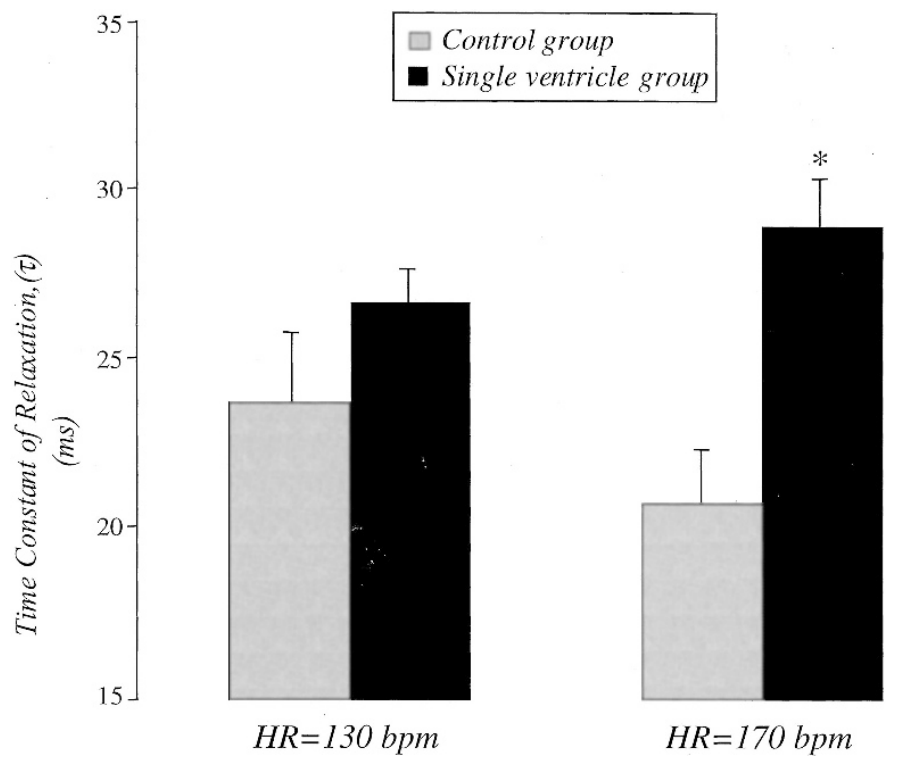

Figure 5. The time constant of ventricular relaxation $(\tau)$, measured at two paced HRs of 130 and $170 \mathrm{bpm}$. At the lower HR of $130 \mathrm{bpm}, \tau$ was similar in both groups, but at the higher HR of $170 \mathrm{bpm}, \tau$ was significantly prolonged in the single-ventricle group, suggesting impaired relaxation of the single ventricle at higher HRs. Error bars represent SD $\left({ }^{*} p<0.01\right.$ between experimental and control groups).

In contrast, in the control subjects, $\tau$ continued to decrease with increasing HR. Therefore, in the control group, the $\mathrm{HR}_{\text {crit }}$ was not reached in the range of HRs studied, suggesting that values of $\mathrm{HR}_{\text {crit }}$ in control patients either equal or exceed 180 bpm (Fig. 6). In the single-ventricle group, $\mathrm{HR}_{\text {crit }}$ was noted at $139.5 \pm 13.1 \mathrm{bpm}$. This indicated that $\mathrm{HR}_{\text {crit }}$ was significantly lowered (shifted to the left) in patients with single ventricles ( $p$ $<0.001)$.

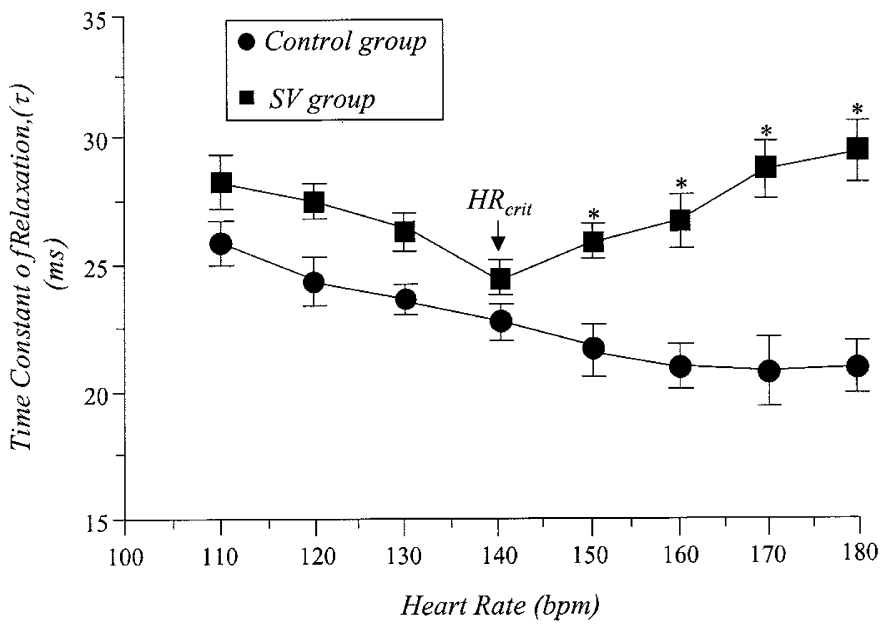

Figure 6. Relaxation-frequency relationship ( $\tau v s$ HR) is depicted for the single-ventricle $(\square)$ and control $(\bullet)$ groups. At lower HRs, $\tau$ was similar in both groups but became significantly prolonged in the single-ventricle group at faster HRs exceeding $140 \mathrm{bpm}\left(\mathrm{HR}_{\text {crit }}\right)$. At higher HRs, the relaxationfrequency relationship changed from negative to positive, creating a significant divergence between the two groups. Error bars represent SE of mean ${ }^{*} p<$ 0.001). SV, single-ventricle group.

\section{Influence of Age}

In the control group, which had a wider age range (0.5-4.8 y), we performed correlations between age and various physiologic indices. Partial correlations of these variables showed a poor correlation. between age and $\mathrm{dP} / \mathrm{dt}_{\max }$ measured at 130 bpm $(r=0.36)$, systolic $\mathrm{HR}_{\text {crit }}(r=0.22)$, diastolic $\mathrm{HR}_{\text {crit }}(r=$ $0.24), \mathrm{T}_{\mathrm{c}}(r=0.24)$, and $\tau$ measured at $130 \mathrm{bpm}(r=0.36)$. This suggested that inclusion of infants and children of different ages did not influence the physiologic indices significantly.

\section{DISCUSSION}

In this study, we evaluated systolic and diastolic properties of the univentricular heart supporting the systemic circulation in children, using invasive indices. Our results indicate that physiologic indicators of $\mathrm{SR} \mathrm{Ca}^{2+}$ release $\left(\mathrm{dP} / \mathrm{dt}_{\text {max }}\right.$, forcefrequency relationship, and MR) are impaired in univentricular hearts. Likewise, physiologic indices of SR $\mathrm{Ca}^{2+}$ uptake $(\tau$, $\mathrm{HR}_{\text {crit }}$, and relaxation-frequency relationship) are also impaired in patients with single ventricles, especially at higher HRs.

\section{Effect on Systolic Properties}

A previous invasive study using stress-volume and stressshortening relationships showed impaired contractile function in univentricular hearts of both LV and RV morphology (19). However, it is interesting that no significant difference in contractile function was noted between the LV and RV morphology in univentricular hearts. In our study, we used an isovolumetric phase index (i.e. $\mathrm{dP} / \mathrm{dt}_{\max }$ ) rather than an ejection-phase index. The advantage of this index is that it is easily measurable; it is more sensitive in detecting contractile dysfunction than ejection-phase indices; it is independent of the shape of the heart; and because it is measured during isovolumetric contraction, it is not influenced by afterload (20). These qualities made it an attractive index for measuring contractile 
function in single ventricles that often have varying shapes and morphologies and in which calculation of ejection-phase indices may be difficult.

Force-frequency relationship. Recent studies have shown that the force-frequency relationship is biphasic, characterized by an initial positive limb and a subsequent negative limb, the change occurring at the $\operatorname{HR}_{\text {crit }}(14,21)$ (see discussion on $\mathrm{HR}_{\text {crit }}$ later). The initial amplification of contraction noted along the positive limb of the force-frequency relationship is characteristic of a healthy left ventricle and is strongly manifested during exercise (22). The increase in contractility is the net result of an increase in cytosolic $\mathrm{Ca}^{2+}$, increasing its availability to the myofilaments $(12,23)$. A recent study in humans with hypertrophic cardiomyopathy showed that impaired force-frequency relationship was associated with decreased expression of SR $\mathrm{Ca}^{2+}$ pump (24). These studies suggest that the force-frequency relationship reflects $\mathrm{Ca}^{2+}$ cycling.

$\boldsymbol{H R}_{\text {crit }}$ Recent transgenic experiments have shown the usefulness of $\mathrm{HR}_{\text {crit }}$ as an indicator of intracellular $\mathrm{Ca}^{2+}$ regulation (21). The $\mathrm{Ca}^{2+}$ uptake by the SR is mediated by SR $\mathrm{Ca}^{2+}$ pump. The function of the $\mathrm{Ca}^{2+}$ pump, in turn, is modulated by phospholamban. Studies on genetically modified mice have shown an inverse relation between phospholamban and $\mathrm{HR}_{\text {crit }}$, such that ablation of phospholamban resulted in a higher $\mathrm{HR}_{\text {crit }}$ (shift to right) whereas overexpression of phospholamban resulted in a lower $\mathrm{HR}_{\text {crit }}$ (shift to left). On the basis of these elegant models, we speculate that the shift to the left of $\mathrm{HR}_{\text {crit }}$ noted in univentricular hearts may indicate impaired $\mathrm{Ca}^{2+}$ cycling by the SR.

MR. MR and $\mathrm{T}_{\mathrm{c}}$ are physiologic expressions of the intracellular $\mathrm{Ca}^{2+}$ concentration and $\mathrm{Ca}^{2+}$ cycling (12). Our study on normal, young $(<3.5 \mathrm{y})$ children demonstrate that the values of $\mathrm{T}_{\mathrm{c}}$ were even shorter $(54.6 \pm 9.8 \mathrm{~ms})$ than their normal, adult counterparts (104.6 $\pm 14.2 \mathrm{~ms})(25)$. This suggests more rapid $\mathrm{Ca}^{2+}$ cycling in young children than adults. However, significant prolongation of $T_{c}$ demonstrated in univentricular hearts raises the possibility of impaired intracellular $\mathrm{Ca}^{2+}$ cycling in these patients. However, other mechanisms (e.g. altered adrenergic signaling, changes in isoform expression, modifications in myosin light chains and thin filaments) may also play a role.

Several previous studies have demonstrated that MR is relatively independent of loading conditions in intact hearts of animals and humans $(16,26)$. This property, therefore, was advantageous in assessing systolic properties in univentricular hearts of various volumes and in children of various sizes.

\section{Effects on Diastolic Properties}

The results of this study show the relaxation property of the single ventricle to be similar to that of the control hearts at lower HRs but significantly different at higher HRs. Previous investigators have suggested that $\mathrm{LV}$ relaxation $(\tau)$ is largely influenced by detachment of actin-myosin cross-bridges and reuptake of $\mathrm{Ca}^{2+}$ into the $\operatorname{SR}(18,27,28)$. Therefore, $\tau$ offers a unique physiologic insight into these intracellular mechanisms in the cardiac myocyte.
Relaxation-frequency relationship. In single ventricles, the relaxation-frequency relationship was biphasic, the transition occurring at the $\mathrm{HR}_{\text {crit }}$ (Fig. 6) (14). Therefore, at higher HRs exceeding $\mathrm{HR}_{\text {crit }}$, there was a clear dichotomy of relaxationfrequency curves between univentricular and control hearts. The inability of the univentricular heart to relax adequately at higher rates may explain the exercise intolerance noted in patients with single ventricles (1). In the control hearts, the relaxation-frequency relationship showed a descending limb only, in the range of HRs studied. Experiments on animals suggest that if we were to pace at faster HRs ( $>180 \mathrm{bpm})$, then we might have achieved the $\mathrm{HR}_{\text {crit }}$ even in the control group. This, however, underscores that in univentricular hearts, $\mathrm{HR}_{\text {crit }}$ is significantly shifted to the left. At the ultrastructural level, studies on transgenic models of phospholamban overexpression (21) have elegantly shown that when the $\mathrm{HR}_{\text {crit }}$ is shifted to the left, it indicates impaired $\mathrm{Ca}^{2+}$ uptake by the SR. At the physiologic level, the decrease in $\mathrm{HR}_{\text {crit }}$ may represent inadequate myocardial perfusion at faster HRs (29).

On the basis of previous studies $(14,21,24)$, we speculated that the physiologic indices used in this study indicate various aspects of $\mathrm{Ca}^{2+}$ cycling. However, by attributing our results to a single subcellular mechanism, we may be ignoring some other important mechanisms. For example, posttranslational modifications in myosin light chains and thin filaments of contractile proteins may produce similar physiologic changes. Alterations in adrenergic signaling (e.g. reduced $\beta$-adrenergic receptors, alterations in $\mathrm{G}$ proteins) may also produce similar changes in the force-frequency relationship (22).

\section{Effect of Preload}

In our study, during assessment of $\mathrm{dP} / \mathrm{dt}_{\max }$, simultaneous preload was not measured. Nevertheless, during increasing HRs, the ventricular end-diastolic pressure decreased, suggesting a corresponding decrease in preload. Such decrease in preload with incremental pacing has actually been documented in conscious animals and humans, in whom preload was assessed from left ventricular end-diastolic dimension $(14,30)$. Therefore, the increase in $\mathrm{dP} / \mathrm{dt}_{\max }$ noted during incremental pacing in our study occurred in the face of decreasing preload and represents a true increase in contractility. Likewise, the decrease in $\mathrm{dP} / \mathrm{dt}_{\max }$ in univentricular hearts occurred, although the chamber volumes were significantly increased. This suggests a true decrease in contractility.

Anderson et al. (30) and others $(15,16)$ have shown that MR is relatively unaffected over a wide range of preload and afterload. This normalization of the $\mathrm{dP} / \mathrm{dt}_{\max }$ of the premature beat by that of the preceding beat eliminated the effects of different preloads created by altering ESIs. For allowing for interpatient comparison, the basic pacing rate and ESIs were held constant in experimental and control groups. This is very important as the time constant of the MR curve depends on the pacing rate (15).

Limitations. One of the important limitations of this study is the modest number of patients. This was because the number of patients with univentricular hearts undergoing cardiac catheterization at a single institution is limited. Moreover, because of the significant invasive nature and the rapid pacing rates 
used in this experiment, it was often difficult to obtain parental consent. Despite a modest number of patients, we have shown extremely divergent findings in patients with univentricular hearts when compared with control subjects, which has contributed to a high degree of statistical significance (very low $p$ values). Future, larger studies may be able to expound on the concepts raised by our study.

The univentricular hearts in our series consisted of both LV and RV morphologies. This heterogeneity was unavoidable in a medium-sized center with a finite number of such patients and in an invasive study that had low enrollment. Because of a low number of patients in each group, we chose not to explore the differences between univentricular hearts of RV and LV morphology.

Unlike the control group, the experimental group had undergone cardiopulmonary bypass during the surgery for the bidirectional Glenn shunt. Previous studies (31-32) have shown that despite undergoing bidirectional Glenn shunt surgery, the systolic function of the univentricular heart was not affected. Therefore, on the basis of these findings, we propose that cardiopulmonary bypass did not significantly affect systolic function in the experimental group. In studies performed under conscious sedation, it is difficult to be sure that all patients were at the same level of sedation and is an inherent limitation of performing hemodynamic research under conscious sedation.

\section{CONCLUSIONS}

Our study evaluated systolic and diastolic properties of the univentricular heart, using invasive indices that have been used as gold standards in assessment of cardiac function. These indices were specifically chosen as previous investigations revealed that these indices may reflect intracellular $\mathrm{Ca}^{2+}$ cycling. In our study, we demonstrated that these indices are indeed impaired in univentricular hearts. However, posttranslational modification of myosin light chains and thin filaments may also produce similar physiologic changes. We theorize that techniques of improving $\mathrm{Ca}^{2+}$ cycling in the cardiac myocyte may improve the functional status of these ventricles. Pharmacologic and genetic manipulations to improve $\mathrm{SR} \mathrm{Ca}^{2+}$ reuptake are presently in progress. It is possible that pharmacologic inhibition of phospholamban, a small protein, may have important therapeutic implications. We speculate that these manipulations, rather than traditional inotropic and lusitropic agents, will form the future cornerstones for improving cardiac function.

Acknowledgment. We thank Dr. David C. Schwartz, former chief of cardiology, Children's Hospital Medical Center, Cincinnati, for support and encouragement during this study. We also thank Drs. Jonathan Rhodes and Hitendra T. Patel from Tufts University School of Medicine, Boston, for carefully reviewing the manuscript.

\section{REFERENCES}

1. Driscoll DJ, Offord KP, Feldt RH, Schaff HV, Puga FJ, Danielson GK 1992 Five-to-fifteen year follow-up after Fontan operation. Circulation 85:469-496
2. Graham TP, Franklin RCG, Wyse RKH, Gooch V, Deanfield JE 1986 Left ventricular wall stress and contractile function in childhood: normal values and comparison of Fontan repair versus palliation only in patients with tricuspid atresia. Circulation 74:I61-I69

3. Sluysmans T, Sanders SP, Vand der Velde M, Matitiau A, Parness IA, Spevak PJ, Mayer JE Jr, Colan SD 1992 Natural history and patterns of recovery of contractile function in single left ventricle after Fontan operation. Circulation 86:753-761

4. Fogel MA, Weinberg PM, Chin AJ, Fellows KE, Hoffman EA 1996 Late ventricular geometry and performance changes of functional single ventricle throughout staged Fontan reconstruction assessed by magnetic resonance imaging. J Am Coll Cardiol 28:212-221

5. Parikh SR, Hurwitz RA, Caldwell RL, Girod DA 1991 Ventricular function in the single ventricle before and after Fontan surgery. Am J Cardiol 67:1390-1395

6. Frommelt PC, Snider AR, Meliones JN, Vermilion RP 1991 Doppler assessment of pulmonary artery flow patterns and ventricular function after the Fontan operation. Am J Cardiol 68:1211-1215

7. Akagi T, Benson LN, Gilday DL, Ash J, Green M, Williams WG, Freedom RM 1993 Influence of ventricular morphology on diastolic filling performance in double-inlet ventricle after the Fontan procedure. J Am Coll Cardiol 22:1948-1952

8. Banerjee A, Mendelsohn AM, Knilans TK, Meyer RA, Schwartz DC 1998 Effect of myocardial hypertrophy on systolic and diastolic function in children: insights from the force-frequency and relaxation-frequency relationships. J Am Coll Cardiol 32:1088-1095

9. Perreault CL, Shannon RP, Komamura K, Vatner SF, Morgan JP 1992 Abnormalities in intracellular calcium regulation and contractile function in myocardium from dogs with pacing-induced heart failure. J Clin Invest 89:932-938

10. Gwathmey JK, Copelas L, MacKinnon R, Schoen FJ, Feldman MD, Grossman W, Morgan JP 1987 Abnormal intracellular calcium handling in myocardium from patients with end-stage heart failure. Circ Res 61:70-76

11. Eising GP, Hammond K, Helmer GA, Gilpin E, Ross J Jr 1994 Force-frequency relations during heart failure in pigs. Am J Physiol 267:H2516-H2522

12. Wier WG, Yue DT 1986 Intracellular calcium transients underlying the short-term force-interval relationship in ferret ventricular myocardium. J Physiol 376:507-530

13. Brutsaert DL, Housmans PR, Goethals MA 1980 Dual control of relaxation: its role in the ventricular function in the mammalian heart. Circ Res 47:637-652

14. Khoury SF, Hoit BD, Dave V, Shao Y, Babel M, Periasamy M, Walsh RA 1996 Effects of thyroid hormone on left ventricular pressure and regulation of contractility and calcium cycling proteins in the baboon: implications for the force frequency and relaxation frequency relationships. Circ Res 79:727-735

15. Burkhoff D, Yue DT, Franz MR, Hunter WC, Sagawa K 1984 Mechanical restitution of isolated perfused canine left ventricles. Am J Physiol 246:H8-H16

16. Vatner DE, Sato N, Kiuchi K, Shannon RP, Vatner SF 1994 Decrease in myocardial ryanodine receptors and altered excitation-contraction coupling early in the development of heart failure. Circulation 90:1423-1430

17. Freeman GL, Colston JT 1990 Evaluation of left ventricular mechanical restitution in closed-chest dogs based on single-beat elastance. Circ Res 67:1437-1445

18. Weiss JL, Frederikson JW, Weisfeldt ML 1976 Hemodynamic determinants of the time-course of fall in canine left ventricular pressure. J Clin Invest 58:751-760

19. Sano T, Ogawa M, Taniguchi K, Matsuda H, Nakajima T, Arisawa J, Shimazaki Y, Nakano S, Kawashima Y 1989 Assessment of ventricular contractile state and function in patients with univentricular heart. Circulation 79:1247-1256

20. Kambayashi M, Miura T, Oh BH, Rockman HA, Murata K, Ross JJ 1992 Enhancement of the force-frequency effect on myocardial contractility by adrenergic stimulation in conscious dogs. Circulation 86:572-580

21. Kadambi VJ, Ball N, Kranias EG, Walsh RA, Hoit BD 1999 Modulation of force-frequency relation by phospholamban in genetically engineered mice. Am J Physiol 276:H2245-H2250

22. Ross JJ, Miura T, Kambayashi, Eising GP, Ryu KH 1995 Adrenergic control of the force-frequency relation. Circulation 92:2327-2332

23. Bers DM 1991 Excitation-Contraction Coupling and Cardiac Contractile Force. Kluwer Academic Publishers, Norwell, MA, pp 155-158, 167-170

24. Somura F, Izawa H, Iwase M, Takeichi Y, Ishiki R, Nishizawa T, Noda A, Nagata K, Yamada Y, Yokota M 2001 Reduced myocardial sarcoplasmic reticulum $\mathrm{Ca}^{2+}$ ATPase mRNA expression and biphasic force-frequency relations in patients with hypertrophic cardiomyopathy. Circulation 104:658-663

25. Liu CP, Ting CT, Lawrence W, Maughan L, Chang MS, Kass DA 1993 Diminished contractile response to increased heart rate in intact human left ventricular hypertrophy: systolic versus diastolic determinants. Circulation 88:1893-1906

26. Anderson PA, Rankin JS, Arentzen CE, Anderson RW 1976 Evaluation of forcefrequency relationship as a descriptor of the inotropic state of the canine left ventricular myocardium. Circ Res 39:832-839

27. Frederiksen JW, Weiss JL, Weisfeldt ML 1978 Time constant of isovolumic pressure fall: determinants in the working left ventricle. Am J Physiol 235:H701-H706

28. Katz AM 1988 Sarcoplasmic reticular control of cardiac contraction and relaxation. In: Grossman W, Lorell BH (eds) Diastolic Relaxation of the Heart. Martinus Nijhoff Publishing, Boston, pp 11-15

29. Aroesty JM, McKay RG, Heller GV, Royal HD, Als AV, Grossman W 1985 Simultaneous assessment of left ventricular systolic and diastolic dysfunction during pacing-induced ischemia. Circulation 71:889-900

30. Anderson PA, Manring A, Serwer GA, Benson DW, Edwards SB, Armstrong BE, Sterba RJ, Floyd RD 1979 The force-interval relationship of the left ventricle. Circulation 60:334-348

31. Lemes V, Ritter SB, Messina J, Gold JP 1995 Enhancement of ventricular mechanics following bidirectional superior cavopulmonary anastomosis in patients with single ventricle. J Card Surg 10:119-124

32. Donofrio MT, Jacobs ML, Spray TL, Rychik J 1998 Acute changes in preload, afterload, and systolic function after superior cavopulmonary connection. Ann Thorac Surg 65:503-508 